\title{
Oxygen saturation, periodic breathing, and sleep apnea in infants aged 1-4 months old living at 3200 meters above sea level
}

\author{
Santiago Ucrós, M.D. ${ }^{a}$, Claudia Granados, M.D. ${ }^{b}$, Karem Parejo, M.D. ${ }^{c}$, Fausto Ortega, M.D. ${ }^{d}$, \\ Fernando Guillén, M.D.e, Sonia Restrepo, M.D.f, Fabián Gil, Master of Science ${ }^{g}$ and Miriam Guillén, student ${ }^{h}$
}

\begin{abstract}
Objectives: To describe, in infants aged 1-4 months old living at 3200 meters above sea level (MASL), oxygen saturation $\left(\mathrm{SpO}_{2}\right)$, sleep apnea indices, and periodic breathing (PB) during sleep. Polysomnographies were done in 18 healthy infants. Results: The median $\mathrm{SpO}_{2}$ was $87 \%$, and the median $\mathrm{PB}$ was $7.2 \%$ for the total sleep time. The median central sleep apnea index was 30.5/hour, which decreased to 5.4/hour once sleep apneas associated with $\mathrm{PB}$ were excluded. The $5^{\text {th }}$ percentile for $\mathrm{SpO}_{2}$ was $76 \%$ among awake infants, and $66 \%$ among asleep infants. Conclusions: The $\mathrm{SpO}_{2}$ waslower than that observed at sea level, whereas PB and the central sleep apnea index were higher, once sleep apneas associated with PB were excluded. The latter was similar to that observed at sea level. At 3200 MASL, different cut-off points are required for a normal $\mathrm{SpO}_{2}$, one for infants during the waking state and one for infants during sleep. Key words: sleep, infant, altitude, oximetry, polysomnography.

http:/ / dx.doi.org/10.5546/aap.2017.eng.54
\end{abstract}

a. Department of Pediatrics. Fundación Santa Fe de Bogotá. Bogotá, Colombia.

b. Department of Pediatrics and Department of Clinical Epidemiology and Biostatistics. Pontificia Universidad Javeriana. Bogotá, Colombia.

c. Department of Neurology and Sleep Center. Fundación Clínica Shaio. Bogotá, Colombia.

d. Department of Pediatrics. Hospital Luis Fernando Martínez. Cañar, Ecuador.

e. Department of Pediatrics. Hospital del Río. Universidad del Azuay. Cuenca, Ecuador.

f. Department of Pediatrics. Hospital de La Misericordia y Fundación Santa Fe de Bogotá, Universidad de los Andes. Bogotá, Colombia.

g. Department of Clinical Epidemiology and Biostatistics. Pontificia Universidad Javeriana. Bogotá, Colombia.

h. Medicine student. Universidad del Azuay. Cuenca, Ecuador.

E-mail address:Santiago Ucrós, M.D.: santiago_ucros@yahoo.com

Funding:

This research was partially funded by the contributions made by the Fundación Conocimiento, in Bogotá, Colombia (Grant PI-FC/001-2012), the Education Fund of the Department of Pediatrics of Fundación Santa Fe de Bogotá, and the Research Fund of Universidad del Azuay in Cuenca, Ecuador.

Conflict of interest: None.

Received: 3-6-2016

Accepted: 8-12-2016

\section{INTRODUCTION}

Hemoglobin oxygen saturation $\left(\mathrm{SpO}_{2}\right)$ in infants has been established in the waking state at different altitudes. ${ }^{1-4}$ However, there are limited data on infants' $\mathrm{SpO}_{2}$ during sleep. Studies have been conducted in this regard in Colombia, ${ }^{5-7}$ Bolivia, ${ }^{1}$ China, ${ }^{3}$ the United States, ${ }^{4}$ and Argentina. ${ }^{8}$ There are no publications available regarding normal $\mathrm{SpO}_{2}$ in infants aged 1-4 months old during sleep at 3000-3500 meters above sea level (MASL) or in relation to periodic breathing (PB) or sleep apnea indices. The only study published on polysomnographies done in infants living above 3500 MASL was conducted in Argentina at 3775 MASL. ${ }^{8}$

In clinical practice, $\mathrm{SpO}_{2}$ during sleep in infants living in high altitudes is commonly misinterpreted because it is based on values obtained from infants during the waking state. This leads to unnecessary hospitalizations, oxygen overuse, and the need to do paraclinical tests to look for an explanation for an alleged hypoxemia. Major consequences result from this situation, both at a financial and an emotional level, and it becomes especially relevant when considering the significance of bronchiolitis in the first months of life.

The main purpose of this study was to describe $\mathrm{SpO}_{2}$ during sleep in infants aged 1-4 months old living at 3200 MASL. The secondary objectives included to describe sleep apnea indices, and PB and its association with $\mathrm{SpO}_{2}$.

\section{METHODOLOGY}

This was a prospective, cross-sectional study conducted in Cañar, Ecuador, at 3200 MASL. The protocol was approved by the Ethics Committees of Fundación Santa Fe de Bogotá, Universidad del Azuay in Ecuador, and Universidad Javeriana in Bogotá. In addition to these institutions, the study also involved investigators from Hospital Luis Fernando Martínez in Cañar (Ecuador), and Clínica Shaio and Hospital de la Misericordia in Bogotá (Colombia). Polysomnographies were performed between December 2012 and December 2013. A descriptive analysis was 
done using median values and percentiles, considering the asymmetrical distribution of data for $\mathrm{SpO}_{2}, \mathrm{~PB}$, and central sleep apnea index (CSAI). $P$ values lower than 0.05 were considered statistically significant.

Infants included in the study were born at term, had a birth weight of at least $2500 \mathrm{~g}$, and had no perinatal or current disease. All study participants were locals and had always lived in Cañar, like their parents. Families who agreed to participate signed an informed consent form. Polysomnographies were performed in a hospital room, where infants were accompanied by their mothers. The BWII system (Neurovirtual, Doral FL, USA) was used to do the polysomnographies, which is approved by the Food and Drug Administration (FDA) and meets the requirements of the American Academy of Sleep Medicine (AASM). $\mathrm{SpO}_{2}$ was measured using a Nonin $8008 \mathrm{~J}$ oximeter (Nonin Medical Inc, Minneapolis, MN). Polysomnographies were required to comprise at least 180 minutes of total sleep time (TST) to be included in the study. Polysomnographies were interpreted as per the AASM's recommendations. The definition of $\mathrm{PB}$ used in this study was that established by the AASM: "PB is classified as an event characterized by 3 or more central apneas of more than 3 seconds in duration, separated by no more than 20 seconds of normal breathing. Central sleep apneas occurred within a periodic breathing episode should also be recorded as a separate apnea event" (i.e., sleep apneas associated with desaturation and/or microarousals). Isolated central sleep apneas were differentiated from those associated with PB by means of an individual analysis for each test.

The sample size was calculated based on estimations made assuming a type I error of 0.05 , a standard deviation of 3.4 for the average $\mathrm{SpO}_{2}$ (based on a study by Universidad del Bosque in Bogotá), ${ }^{5}$ with a $95 \%$ confidence interval and a $2 \%$ absolute accuracy.

To establish if there was a correlation between $\mathrm{SpO}_{2}$ and $\mathrm{PB}$, the relationship between time (minutes) elapsed with a $\mathrm{SpO}_{2} \geq 88 \%$ and time (minutes) elapsed with a $\mathrm{SpO}_{2}<88 \%$ was determined. This cut-off point was selected based on the median $\mathrm{SpO}_{2}$. This coefficient was referred to as sleep saturation coefficient (SSC) and it was used to establish a correlation between $\mathrm{SpO}_{2}$ and PB, which was assessed using the Spearman's test.

\section{RESULTS}

Out of 35 infants who had a polysomnography done, 18 met the minimum time requirement. $\mathrm{SpO}_{2}, \mathrm{~PB}$, and CSAI had an abnormal distribution, with a clear deviation towards the right. The main results are summarized in Table 1.

The median $\mathrm{SpO}_{2}$ was $87 \%$; the difference in $\mathrm{SpO}_{2}$ between the $\mathrm{P} 5$ and the $\mathrm{P} 25$ was $20 \%$, whereas it was 5\% between the P25 and the P95 (Figure 1). The lowest recorded $\mathrm{SpO}_{2}$ was 33\%. The median $\mathrm{SpO}_{2}$ among awake infants was $89 \%$ (P5 76\%-P95 91\%).

The median PB was $7.2 \%$. The median CSAI was 30.5 /hour and the median isolated central sleep apnea index (ICSAI) was 5.4/hour, whereas the median CSAI associated with PB was 19.9/ hour. The average duration of central sleep

TABLE 1. Respiratory parameters of polysomnographies done in 18 infants aged 1-4 months old at 3200 MASL

\begin{tabular}{|c|c|c|c|}
\hline Age (weeks) & Average 8.1 & SD 3.3 & \\
\hline TST (minutes) & Average 229.4 & SD 35.9 & \\
\hline REM sleep time (minutos/\%) & Average $99.4(43.2 \%)$ & SD 27.3 & \\
\hline Non-REM sleep time (minutos/\%) & Average 129.7 (56.7\%) & SD 27.1 & \\
\hline $\mathrm{SpO}_{2}$ in the waking state & Median 89\% & p5 76\% & p95 91\% \\
\hline $\mathrm{SpO}_{2}$ during TST & Median $87 \%$ & p5 66\% & p95 91\% \\
\hline PB during TST & Median $7.2 \%$ & p5 1.2\% & p95 78.7\% \\
\hline TCSAI/hour & Median 30.5 & p5 8.8 & p95 217.5 \\
\hline ICSAI/hour & Median 5.4 & p5 2.0 & p95 85.8 \\
\hline CSAIAPB/hour & Median 19.9 & p5 2.2 & p95 204.4 \\
\hline Lowest $\mathrm{SpO}_{2}$ recorded in each test & Median $71 \%$ & p5 31\% & p95 81\% \\
\hline
\end{tabular}

REM: rapid eye movement; SD: standard deviation; SpO2: oxygen saturation; TST: total sleep time; P: percentile; PB: periodic breathing; TCSAI: total central sleep apnea index; ICSAI: isolated central sleep apnea index; CSAIAPB: central sleep apnea index associated with periodic breathing. 
apneas was 5.7 seconds (SD 1.0). The median central hypopnea value was 0 ; the same value was obtained for obstructive and mixed sleep apneas. The median SSC was 1.15. No correlation was observed between PB and SSC $(r=-0.36, p=0.14)$.

\section{DISCUSSION}

In this study, we describe $\mathrm{SpO}_{2}$ and other polysomnography respiratory parameters in infants aged 1-4 months old at 3200 MASL. The median $\mathrm{SpO}_{2}$ was $88 \%$, which was lower than that reported at sea level, where infants aged 1-4 months old had a $\mathrm{SpO}_{2}$ of $98.1 \%,{ }^{9}$ and was also lower than that reported by us at 2560 MASL, which was $92 \%{ }^{6}$ The $\mathrm{P} 5$ of $\mathrm{SpO}_{2}$ was $76 \%$ among

FIGURE 1. Oxygen saturation percentiles during sleep in 18 infants aged 1-4 months old at 3200 MASL

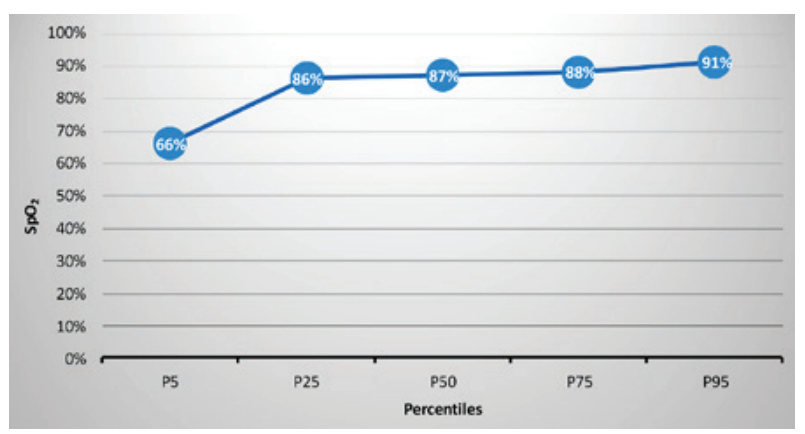

$\mathrm{SpO}_{2}$ : oxygen saturation.

Figure 2. Oxygen saturation. Percentiles 5 and 95 for sea level, 2560 MASL, and 3200 MASL in infants aged 1-4 months old during sleep

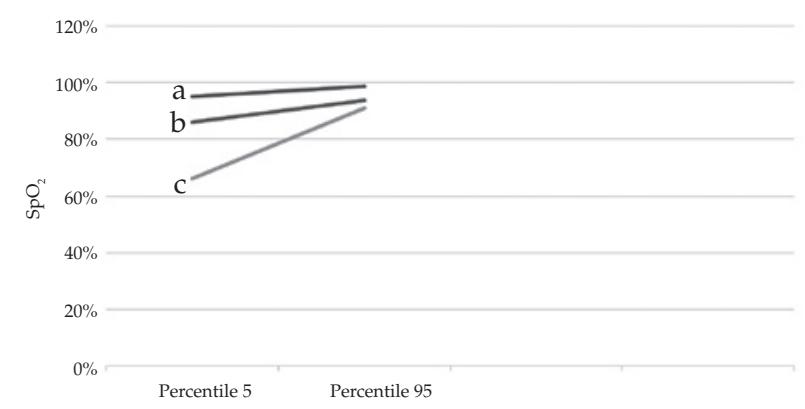

$\mathrm{SpO}_{2}$ : oxygen saturation.

a. Sea level: ref. 11 .

b. 2560 MASL: ref. 6 .

c. 3200 MASL: this study. awake infants and $66 \%$ among asleep infants; this means that, at this altitude, it is necessary to have two different cut-off points for a normal $\mathrm{SpO}_{2}$ of younger infants, depending on whether it is measured during the waking state or during sleep. This does not occur at sea level, where the $90 \%$ value is useful for both awake and asleep infants (Figures 2 and 3). This is a highly relevant issue for acute respiratory tract infection programs where pulse oximetry has become an essential tool for making clinical decisions..$^{10,11}$

The median PB was $7.2 \%$ and was significantly higher than that published at sea level, which was reported to be $1.1 \%$ among young infants, ${ }^{12}$ and was also higher than that reported at 2560 MASL, which was $4.9 \%{ }^{6}$ The CSAI was higher than that observed at $2560 \mathrm{MASL}^{6}$ and much higher than that published at sea level. Once central sleep apneas associated with PB are excluded, the CSAI was similar to that observed at sea level; this confirms that the difference between isolated central sleep apneas and those associated with $\mathrm{PB}$ was critical in this age group living in high altitudes.

The lack of a correlation between $\mathrm{SpO}_{2}$ (assessed as per the SSC) and PB suggests that the lower $\mathrm{SpO}_{2}$ compared to that observed at sea level may be explained by the reduced oxygen pressure typical of high altitudes, not by the increase in PB. In this study, no obstructive or mixed sleep apneas were observed, neither were they found previously in this age group at both sea level ${ }^{9}$ and in high altitudes. ${ }^{6}$

FIGURE 3. Lower limit of normal of oxygen saturation in infants aged 1-4 months old during the waking state versus during sleep at sea level and at 3200 MASL

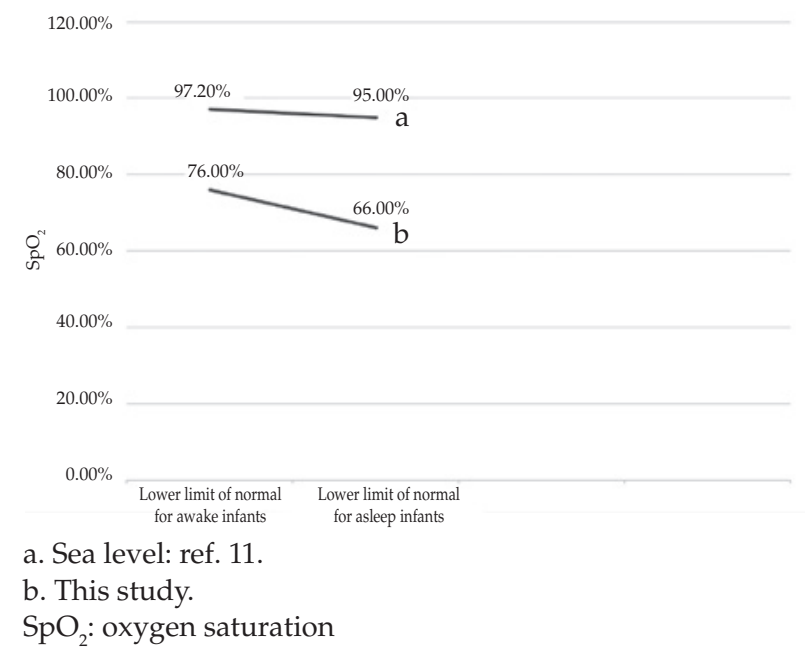


The fact that $25 \%$ of infants have a $\mathrm{SpO}_{2}$ that is significantly different from the remaining $75 \%$ may be explained by a higher pulmonary vascular reactivity (PVR). Studies conducted in Kyrgyzstan ${ }^{13}$ have demonstrated that pulmonary pressure at high altitudes is genetically determined by mediators that regulate PVR. We believe that PVR may be a determining factor for the fact that some individuals have a significantly lower $\mathrm{SpO}_{2}$ during sleep. An early detection of these individuals may be useful to establish their risk for pulmonary hypertension.

A limitation of this study is that out of the 35 infants who had a polysomnography done, only 18 were included because the rest did not reach a TST of at least 180 minutes.

\section{CONCLUSIONS}

At $3200 \mathrm{MASL}, \mathrm{SpO}_{2}$ among healthy infants aged 1-4 months old was lower than that observed at sea level, whereas PB and CSAI were higher. However, once central sleep apneas associated with PB are excluded, the CSAI was similar to that observed at sea level. At 3200 MASL, different cut-off points are required for a normal $\mathrm{SpO}_{2}$, one for infants during the waking state and one for infants during sleep.

\section{Acknowledgments}

We would like to thank the parents of participating infants for making this study possible. We would also like to thank Sandra Rocío Morales for her help with training on study techniques, and Marta Pizano for her help with the translation from/into English.

\section{REFERENCES}

1. Salas AA. Pulse oximetry values in healthy term newborns at high altitude. Ann Trop Paediatr 2008;28(4):275-8.

2. Gonzáles GF, Salirrosas A. Arterial oxygen saturation in healthy newborns delivered at term in Cerro de Pasco (4340 m) and Lima (150 m). Reprod Biol Endocrinol 2005;3:46.

3. Niermeyer S, Yang P, Shanmina, Drolkar, et al. Arterial oxygen saturation in Tibetan and Han infants born in Lhasa, Tibet. N Engl J Med 1995;333(19):1248-52.

4. Niermeyer S, Shaffer EM, Thilo E, Corbin C, et al. Arterial oxygenation and pulmonary arterial pressure in healthy neonates and infants at high altitude. J Pediatr 1993;123(5): 767-72

5. Torres Y, Osorio L, Ramos N. Medición de los valores de oximetría de pulso durante sueño, vigilia y succión en neonatos sanos en Bogotá (2640 metros de altura sobre el nivel del mar). Avances Pediátricos 1999;1:2-8.

6. Ucrós S, Granados C, Parejo K, Guillén F, et al. Saturación de oxígeno, respiración periódica y apnea durante el sueño en lactantes de 1 a 4 meses a 2560 metros de altura. Arch Argent Pediatr 2015;113(4):341-4.

7. Duenas-Meza E, Bazurto-Zapata MA, Gozal D, GonzálezGarcía M, etal. Overnight polysomnographic characteristics and oxygen saturation of healthy infants, 1 to 18 months of age, born and residing at high altitude (2,640 meters). Chest 2015;148(1):120-7.

8. AlduncinJ, Grañana N, FollettF, MusanteG, etal.Problemas respiratorios durante el sueño en lactantes nativos del altiplano argentino. Arch Argent Pediatr 2005;103(1):14-22.

9. Schlüter B, Buschatz D, Trowitzsch E. Perzentilkurven polysomnographischer parameter für das erste und zweite Lebensjahr. Somnologie (Berl) 2001;5(1):3-16.

10. Cunningham S, Rodríguez A, Adams T, Boyd KA, et al. Bronchiolitis of Infancy Discharge Study (BIDS) group. Oxygen saturation targets in infants with bronchiolitis (BIDS): a double-blind, randomised, equivalence trial. Lancet 2015;386(9998):1041-8.

11. Duke T1,Subhi R,PeelD, Frey B.Pulseoximetry: technology to reduce child mortality in developing countries. Ann Trop Paediatr 2009;29(3):165-75.

12. Brockmann PE, Poets A, Poets CF. Reference values for respiratory events in overnight polygraphy from infants aged 1 and 3 months. Sleep Med 2013;4(12):1323-7.

13. Aldashev AA, Sarybaev AS, Sydykov AS, Kalmyrzaev $\mathrm{BB}$, et al. Characterization of high-altitude pulmonary hypertension in the Kyrgyz: association with angiotensinconverting enzyme genotype. Am J Respir Crit Care Med 2002;166(10):1396-402. 